Uludag Univ. J. Fac. Vet. Med.

36 (2017), 1,2: 29-32

\title{
Merinos Irkı Bir Kuzuda Polimelia
}

\author{
Geliş Tarihi:01.03.2017 \\ Düzeltme Tarihi: 22.06.2017, Kabul Tarihi: 15.12.2017 \\ Melike AKBALA ${ }^{1}, \quad$ Hilal ÇEŞME ${ }^{1}, \quad$ Volkan IPEK $^{2}, \quad$ Hakan SALCI $^{1}$
}

\begin{abstract}
Özet: Merinos 1rk1, 15 günlük, erkek bir kuzu doğuştan beş bacaklı olma anamnezi ile kliniklerimize sevk edildi. Vital parametreleri normal olan kuzuda, inspeksiyonda sağ articulatio humerinin caudalinde, lateral toraks duvarına bağlı fazla bir ekstremite görüldü. Ekstremitede carpal ekleminin distalinden itibaren birleşik 4 adet metacarpus, 2 adet metacarpophalengeal eklem ve iki ayağın geliştiği gözlendi. Antebrachium bölgesinde açık kırığı mevcuttu. Radyolojik olarak 4 ve 5 . kostalar düzeyinde rudimenter bir skapulanın olduğu, humerus ve antebrahium hipoplazisi ve antebrahium'da orta diyafizer kırı saptandı. Metacarpus distalinden itibaren iki farklı metacarpusa dönüşüyordu ve iki adet metacarpophalengeal eklem ve 4 adet digiti'nin mevcut olduğu görüldü. Polimelia tanısı konuldu ve genel anestezi altında ilgili ekstremite operatif olarak vücuttan uzaklaştıııldı. Makroskopik incelemede radyolojik bulgular doğrulandı. Sunulan bu olgu ile Merinos ırkı bir kuzuda polimelia anomalisinin klinik ve radyolojik bulguları ile cerrahi tedavisi rapor edilmiş̧ir.
\end{abstract}

Anahtar Kelimeler: Polimelia, kuzu.

\section{Polymelia in a Merinos Breed Lamb}

\begin{abstract}
A Merinos breed, fifteen-day-old, male lamb was referred to our clinics with the anamnesis of congenital five extremities presentation. In the inspection, an excessive extremity was observed at the caudal site of the right articulatio humeri, connected the lateral thoracic wall in lamb, whose vital parameters were normal. A development of four unified metacarpus extending to the distal part of the carpal joint, two metacarpophalangeal joint and two foot were seen in the extremity. There was an open fracture at the region of antebrachium. Radiologically, a rudimental scapula at the level of 4 and 5th costa, hypoplasia of the humerus and antebrachium, and a middle diaphysial fracture of antebrachium was determined. Distal part of the metacarpus was forming four different metacarpuses, and presence of two metacarpophalangeal joints and four digits was seen. Polymelia was diagnosed and the extremity was removed surgically from the body under general anesthesia. In the macroscopic examination, radiological results were confirmed. With the presentation of this case, anomaly of polymelia in a Merinos breed lamb was reported with the clinical and radiological results as well as surgical treatment.
\end{abstract}

Key Words: Polymelia, lamb.

\section{Giriș}

Evcil hayvanlarda karşılaşılan kongenital anomaliler, vücudun tüm sistemlerinde oluşabilmektedir ${ }^{5,8,9}$. Genellikle kas-iskelet sistemine ilişkin anomalilere daha sıklıkla rastlanmakta- dir ${ }^{2,5,9,12}$. Embriyonal ya da fötal dönemde gelişen kongenital anomaliler insan ve hayvanlarda organ ya da sistemlerde yapisal ve fonksiyonel bozukluklara yol açmaktadır ${ }^{9,11}$. Bu anomalilerin resesif genlerin neden olduğu (kalıtımsal) düşünülmektedir ${ }^{2-5,8,12}$. Oluşumlarında endojen

1 Uludağ Üniversitesi, Veteriner Fakültesi, Cerrahi Anabilim Dalı, 16059, Bursa. hsalci@uludag.edu.tr

2 Uludağ Üniversitesi, Veteriner Fakültesi, Patoloji Anabilim Dalı, 16059, Bursa. 
(kromozom anomalisi veya gen mutasyonu vb.) veya fiziksel, kimyasal, viral, alimenter, fertilizasyon tekniği, hormonal ve antikorlar vb. nedenlerin rol oynadığ $\breve{g}$ kabul edilmektedir ${ }^{3-5,8-10,12}$.

Polimelia ya da fazla sayıda ektopik ekstremite olarak tanımlanan olgu, özellikle ruminantlarda rastlanılmakla birlikte evcil hayvanlarda nadiren görülmektedir ${ }^{1,2,4,7,9,10}$. Ekstremitelerin tamamen yokluğu amelia, ön ekstremitelerin yokluğu amelia anterior (abrachi), arka ekstremitelerin yokluğu ise amelia posterior (apodie) olarak ifade edilmektedir ${ }^{3,6,8}$. Ön ya da arka ekstremitelerden birinin yokluğu monomelie olarak tanımlanırken, ekstremitelerin normalden fazla sayıda olması ise polimelia olarak adland1rılmaktadır ${ }^{1,3,8,9}$. Polimelia olgularının buzağ ${ }_{1}$, koyun, keçi, tavuk ve insanlarda rapor edildiği bildirilmektedir ${ }^{1,3,4,8,9,12}$. Sunulan bu olguda Merinos ırkı bir kuzuda karşılaștığımız polimelia olgusunun klinik ve radyolojik bulguları ile cerrahi sağaltımı rapor edilmiştir.

\section{Olgunun Tanımı}

Merinos 1rk1, 15 günlük, erkek bir kuzu doğuştan beş bacaklı olma ve fazla olan bacağ1nın hayvanın yürüyüşüne engel olması şikayetleriyle Uludağ Üniversitesi Veteriner Fakültesi Cerrahi Anabilim Dalı Klinikleri'ne getirildi.

İnspeksiyonda sağ articulatio humerinin caudalinde, lateral toraks duvarına bağlı fazla bir ekstremitenin bulunduğu görüldü. Ekstremitenin metacarpusu hizasızda, distalden itibaren 4 adet metacarpusun geliştiği, 2 adet metacarpophalengeal eklemin bulunduğu belirlendi. En distalde parmak sayıları normal 2 adet ayak bulunmaktaydı. Ayrica antebrachium düzeyinde açık bir kırığın olduğu ve kırık bölgesinden irinli akıntının geldiği tespit edildi (Şekil 1).

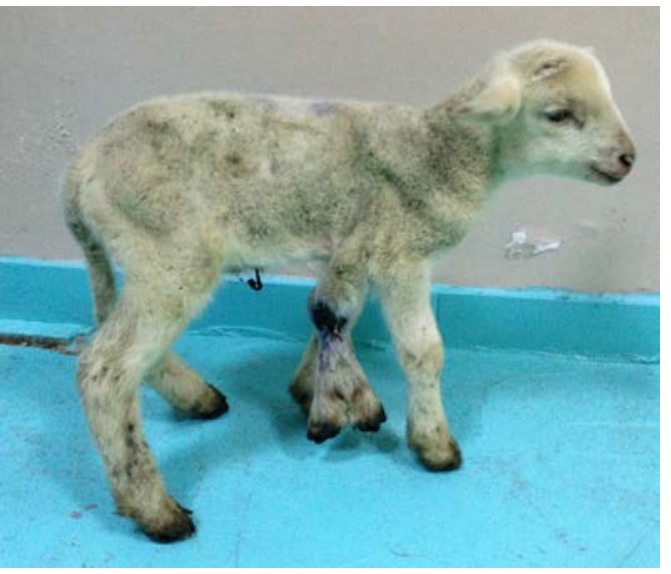

Şekil 1. Olgunun klinik görünümü.

Figure 1. Clinical aspect of the case.
Radyolojik olarak mediolateral ve craniocaudal radyografilerde 4 ve 5 . costalar düzeyinde rudimenter bir scapulanın mevcut olduğu, humerus ve antebrachium'un tam olarak gelişmediği görüldü. Antebrachium'da orta diyafizer parçalı bir kırık saptandı. Metacarpusun distal diafiz kısmında iki adet metacarpusun geliştiği ve ayrı olarakta iki adet metacarpophalengeal eklem ve 4 adet digitinin mevcut olduğu görüldü (Şekil 2a-b). Klinik ve radyolojik bulgular temelinde polimelia tanıs1 konuldu ve hasta sahibinden alınan izinle operatif olarak fazla ekstremitenin uzaklaştırılmasına karar verildi.

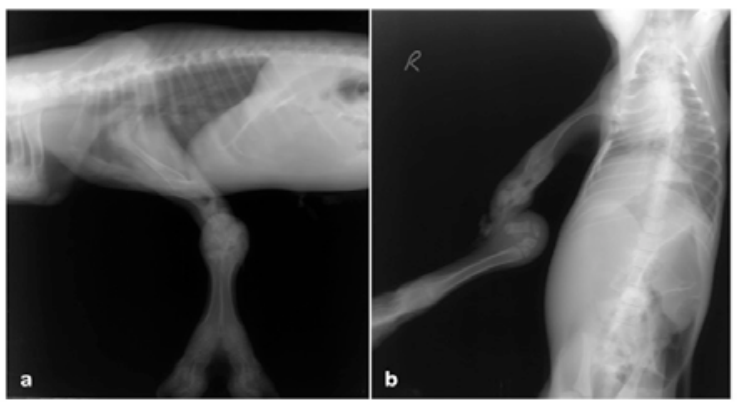

Şekil 2. Olgunun lateral (a) ve ventrodorsal (b) radyografileri. Ektopik fazla ekstremitedeki anatomik oluşumların radyolojik görünümleri.

Figure 2. Lateral (a) and ventrodorsal (b) radiographs of the case. Radiological views of the anatomical structures in supernumerary ectopic limb.

Premedikasyon amaciyla $0,15 \mathrm{mg} / \mathrm{kg}$ dozda xylazine $\mathrm{HCl}$ (Alfazine ${ }^{\circledR}$,Egevet, Türkiye) im. olarak verildi. Takiben $4 \mathrm{mg} / \mathrm{kg}$ dozda im. ketamin $\mathrm{HCl}$ (Alfamine ${ }^{\circledR}$, Egevet, Türkiye) ile indüksiyon sağlandi. Gerektiğinde idame olarak ketamin $\mathrm{HCl}$ ve diazepam $\left(\right.$ Diazem $^{\circledR}$, Deva, Türkiye) kombinasyonu iv. olarak verildi.

Kuzu; ilgili ekstremite yukarıda kalacak şekilde lateral pozisyonda operasyon masasina yatırıldı. Săg toraks duvarı ve ekstremitenin toraksa bağlandığ 1 kısmın tıraş ve dezenfeksiyonu gerçekleştirildikten sonra bölge steril örtülerle sınırlandi. Toraks duvarına ekstremitenin bağlandığ $\breve{g}_{1}$ ksmın cevresinde deriye kavun dilimi ensizyon yapıldı. Derialtı yumuşak dokular ve kaslar disseke edildi, intercostal kaslara bağl1 bulunan rudimenter scapulayla birlikte ekstremitenin toraks duvarından eksizyonu gerçekleştirildi. Kanama kontrolü sonrasında kaslar, yumuşak dokular ve deri kuralına uygun bir şekilde kapatıld1. 
Postoperatif radyografilerde toraks duvarının bütünlügünün korunduğu ve herhangi bir intratorasik komplikasyonun (pnömotoraks) şekillenmediği belirlendi (Şekil 3a-b). Hasta sahibine, postoperatif 5 gün süreyle parenteral antibiyotik ve analjezik ilaç uygulaması yönünden reçete hazırlandı. Ayrıca hasta sahibine kuzuyu ayrı bir boksta tutması,operasyon yarasının antiseptik uygulanarak günlük lokal bakımı ve dikişlerin 10 gün sonra alınması istendi. Kuzu taburcu edildi.

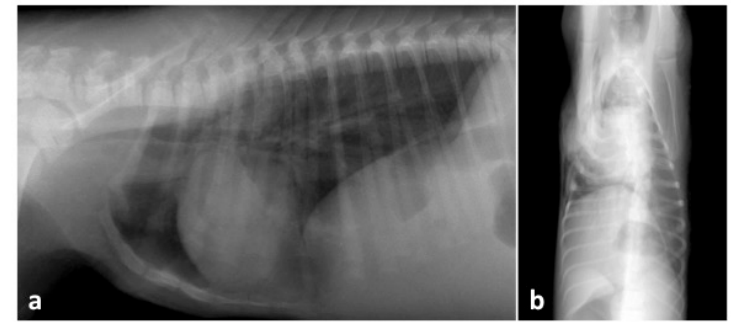

Şekil 3. Olgunun postoperatif lateral (a) ve ventrodorsal (b) radiografileri, toraksa ilişkin herhangi bir patoloji yok.

Figure 3. Postoperatif lateral (a) and ventrodorsal (b) radiographs of the case. There is no pathology in the toraks.

Uzaklaştırılan ekstremitenin patolojik incelemesinde radyolojik bulgularla uyumlu art. humerinin, humerusun, art. cubiti'nin, antebrachium ve art. carpi'nin normal anatomik yapıya sahip olduğu, metacarpusların distal diafizden itibaren iki adet fonksiyonel organellere sahip ayak yapısıyla devam ettiği doğrulandı.

\section{Tartışma}

Ekstremitelerin fazla sayıda olması polimelia olarak tanımlanırken ${ }^{4,6-8,11}$, fazla ekstremite, normal ekstremitenin yanında ya da ekstremiteye bağl1 ise "hakiki polimelia" olarak adlandırılmaktadır. Fazla ekstremite sirttaysa notomelia, sağrıdaysa pygomelia, pelvis ventralindeyse pelvomelia, karın duvarındaysa gastromelia, göğüs duvarının yanındaysa torakomelia ve baş bölgesinde ise cephalomelia ismini almaktadır ${ }^{1-4,6-8,10-12}$. Genelde bu fazla ekstremite scapulanın arkasında ve sağ tarafta şekillenmekte$\operatorname{dir}^{1,8,9}$. Sunduğumuz bu olguda karşılaştı̆̆ımız fazla ekstremite sağ tarafta, scapulanın arka kısminda art. cubiti'ye yakındı ve ayrıca fazla ekstremite toraks duvarıyla bağlantılıydı (torakomelia). Fazla ekstremitenin fonksiyonel ekstremiteye daha yakın olmasından dolayı biz bu olguyu polimelia olarak adlandırdık.
Fazla ekstremite normalden küçükse hayvanın hareketine engel olmaz ancak büyük olduğu durumlarda yürüyüşte topallık ve hayvanın normal anatomofizyolojisini etkileyerek bulunduğu regioya spesifik klinik bulgularla karşımıza çıkmaktadır ${ }^{6,8}$. Aldığımız anamnezde hasta sahibi ilgili ekstremitenin hayvanın normal hareketlerine engel olduğunu bize bildirdi. Ancak klinik olarak olgumuzda fazla ekstremite nedenli topallık vb. bir bulgu ile karşılaşmadık.

Klinik olarak fazla olan ekstremitenin vücuda bağlandığı noktada tek bir anatomik oluşum görülür ve distale doğru inildikçe bu anatomik oluşumun sayıca arttığ gözlenir $^{1,7,8,10-12}$. İnspeksiyon muayenemizde ve radyolojik incelemelerde literatürlerde belirtildiği üzere anatomik oluşumlarda sayıca artış tespit ettik. Metacarpusun distal diafiz kısmında iki adet metacarpus ve ayrı olarak iki adet metacarpophalengeal eklem ve 4 adet digiti saptandi.

Kongenital anomalilerin tanısinda yardımc1 tanı yöntemlerinden yararlanılmakta$\mathrm{d}^{8} \mathrm{r}^{8,9,12}$. Bu amaçla radyoloji, ultrasonografi, bilgisayarlı tomografi ve magnetik rezonans görüntüleme teknikleri kullanılır ${ }^{5}$. Polimelia olguları doğum sonrası klinik olarak tanınmakla birlikte fazla olan ekstremitenin regional bağlantısının tespiti için radyolojik muayene kesinlikle gerekmektedir ${ }^{8,9,12}$. Bu amaçla olgumuzda yardımcı tanı yöntemi olarak radyolojik muayeneden yararland $1 \mathrm{k}$ ve fazla olan ekstremitenin vücuda bağlantı noktası ile ilgili ekstremitedeki fazla olan organ ve organellerin radyolojik muayene ile tespitini gerçekleştirdik.

Kongenital anomali olgularında cerrahi müdahale olgudaki anomalinin büyüklügüne göre değişmektedir ${ }^{5}$. Cerrahi olarak fazla olan ekstremitenin doğum sonrası 1 hafta içerisinde vücuttan uzaklaştırılması hayvanın gelişimi açısından önemli olup gelişimini hızlandırmaktadır ${ }^{2,8,11}$. Eğer polimelia tablosu multiple olarak başka anomalilerle birlikte bulunuyorsa, hayvanın genel durumu ve prognoz değerlendirilerek ya hastanın kesime sevk edilmesi ya da erken cerrahi müdahale ile ilgili ekstremitenin uzaklaştırılması düşünülmelidir ${ }^{1-3,11}$. Sunulan olgumuzda hasta sahibinin tedavi isteği de göz önüne alınarak genel anestezi altında fazla olan ekstremite cerrahi olarak vücuttan uzaklaştırıldı. Postoperatif olarak herhangi bir komplikasyonla karşılaşılmadı.

Sonuç olarak, polimelia olgularının klinik ve radyolojik muayeneler ile detaylı olarak tanınabileceği ve cerrahi müdahale ile fazla olan 
ekstremitenin başarılı bir şekilde vücuttan uzaklaştırılabileceğini Merinos 1rkı bir kuzuda karş1laştığımız bu olgu ile veteriner hekim meslektaşlarımıza sunarız.

\section{Kaynaklar}

1. Barua, P.M., Kalita, D., Sarma, D.K., Kalita, M., Das, P., Lahkar, D. 2014. Polymelia in a crossbred Jersey cow (Bos Taurus): A case report. Int J Med Sci, 5(3): 96-98.

2. Eftekhari, Z., Nourmohammadzadeh, F., Jeloudari, M., Alighazi, N., Mohsenzadeghan, A. 2012. Supernumerary ectopic limb in lamb: a case report. Comp Clin Path, 21: 1207-1209.

3. Hayat, A. 2013. Bir buzağıda notomeli (notomelia) ve pakomeli (phocomelia) olgusu. Harran Üniv Vet Fak Derg, 2(2): 109-111.

4. Karadağ, H., Gül, Y., Dönmez, H.H. 1992. İlginç bir polymelia (thoracomelia ve pelvomelia) olgusu. S Ü Vet Fak Derg, 8(2): 77-79.

5. Kaya, M., Okumuş, Z., Doğan, E., Çetin, E.M., Yanmaz, L.E. 2011. Erzurum Yöresindeki Buzağılarda Doğmasal Anomalilerin görülme sıklığg ve sağkalım oranları. Firat Üniv Săg Bil Vet Derg, 25(2): 83-93.
6. Khan, L.A., Khan, K.M., Ali, S.S., Siddiqui, M.F.M.F. 2013. A rare case of thoracomelia in a goat kid. Vet Pract, 14(1): 78.

7. Kim, C., Yeon, S., Cho, G., Lee, J., Choi, M., Won, C., Kim, J., Lee, S. 2001. Polymelia with two extra forelimbs at the right scapular region in a male Korean native calf. J Vet Med Sci, 63(10): 1161-1164.

8. Koç, Y., Avki, S., Alkan, F. 1995. Beş aylık İvesi bir kuzuda polimelie. Vet Bil Derg, 11(2): 131133.

9. Monfared, A.L. 2013. A case report of supernumerary ectopic limbs in a lamb: anatomical and radiological aspects. Glob Vet, 10(4): 424-426.

10. Nowacka, J., Urbaniak, K., Antosik, P., Jaskowski, J.M., Frackowiak, H., Switonski, M. 2007. Polymelia associated with frequent chromosome breaks in a heifer. Vet Rec, 161: 276-277.

11. Özak, A., Nisbet, H.Ö., Yardımcı, C. 2009. İki buzağıda karşılaşılan polimeli olgusu. Ankara Üniv Vet Fak Derg, 56: 305-307.

12. Shojaei, B., Masoudifard, M., Asadi, A. 2007. Notomelia and ulnar dimelia in a calf: radiographical anatomical aspects. Iran J Vet Surg, 2(4): 83-88. 